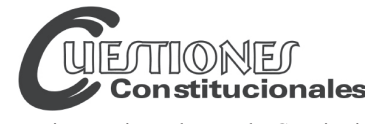

Revista Mexicana de Derecho Constitucional

Núm. 27, julio-diciembre 2012

\title{
LA PRAXIS DE LOS DERECHOS HUMANOS EN MÉXICO A PARTIR DE LA REFORMA CONSTITUCIONAL DE JUNIO DE 2011
}

\author{
HUMAN RIGHTS PRAXIS IN MEXICO \\ AFTER THE CONSTITUTIONAL AMENDMENT \\ OF JUNE 2011
}

\author{
Hugo Saúl Ramírez GarcíA* \\ José Antonio SÁNCHEZ BARROSO**
}

\begin{abstract}
RESUMEN: En este artículo se describen los antecedentes y el contenido de la reforma a la Constitución Política de los Estados Unidos Mexicanos en materia de derechos humanos de junio de 2011, y se formulan una serie de razonamientos críticos a la misma a partir del significado práctico que se ha reconocido a la dignidad humana, como principio práctico fundamental.
\end{abstract}

Palabras clave: derechos humanos; reforma constitucional; principio de dignidad humana.
ABSTRACT: This article describes the background and object of the human rights amendment, established on the Mexican Constitution on june 2011; it also offers a critical approach on this amendment process based on the meaning of human dignity, considered as a fundamental practical principle.

* Doctor en Derecho por la Universidad de Valencia, profesor-investigador en la Facultad de Derecho de la Universidad Panamericana, Campus Ciudad de México.

** Doctor en derecho por la la Universidad Nacional Autónoma de México; profesorinvestigador en la Facultad de Derecho de la Universidad Panamericana, Campus Ciudad de México. 


\section{INTRODUCCIÓN}

Con algunos antecedentes relevantes de por medio, en el 2000 inició la reforma a la Constitución Política de los Estados Unidos Mexicanos (CPEUM), en materia de derechos humanos la cual concluyó, en primera instancia, con la publicación que se hizo de la misma el 10 de junio de 2011 en el Diario Oficial de la Federación. Ésta, como todas las reformas a la CPEUM, tiene el propósito —al menos en teoría - de actualizar el texto constitucional y hacer que éste responda a las necesidades y retos que impone la realidad política, económica, cultural y social del país.

La enmienda constitucional a la que nos venimos refiriendo se inscribe en un escenario de modificaciones de vital importancia tanto por el número de ellas, como por los distintos ámbitos político-sociales que abarcan. En los últimos tiempos se ha hablado mucho de la necesidad de una "nueva Constitución" que verdaderamente atienda a las exigencias ya mencionadas. ${ }^{1}$ Se mira con bastante recelo el contenido y la técnica jurídica de la Constitución de 1917, y más aún su aplicación en el siglo de la tecnología, de la información, de la innovación y del cambio, es decir, en el siglo XXI. Pero no hay que olvidar que las leyes fundamentales de nuestro país no han sido, en general, producto del pacto social, sino de la revolución o de la fuerza imperiosa de un gobierno dispuesto a convertir su proyecto o sus circunstancias en ley suprema de la nación. ${ }^{2}$

En este sentido, hay que tener presente que desde el 5 de febrero de 1917, fecha en que se promulga la CPEUM, hasta el 13 de octubre de 2011, fecha de la última reforma publicada, han existido 199 Decretos de reforma constitucional. De 2000 a la fecha se han publicado 52 Decretos de reforma, lo que equivale aproximadamente al $25 \%$ del texto original de la CPEUM. ${ }^{3}$

1 Desde el ámbito académico, una voz autorizada que se ha postulado en este sentido ha sido la de Jaime Cárdenas Gracia. A su juicio, que asume como compartido por diversos actores políticos, una nueva constitución para México debe conciliar formalidad con realidad, detallando procedimientos políticos de organización social capaces de superar las carencias institucionales que impiden una auténtica reforma del Estado que, en definitiva, permita a la población acceder a los beneficios que supone un régimen democrático. Cfr., Cárdenas, Jaime, Una constitución para la democracia, Instituto de Investigaciones Jurídicas, México, 2000, pp. 34 y 35.

2 García Ramírez, Sergio y Morales Sánchez, Julieta, La reforma constitucional sobre derechos humanos (2009-2011), México, Porrúa, 2011, pp. 29 y 30.

3 http://www.diputados.gob.mx/LeyesBiblio/ref/cpeum_crono.htm, consultada el 15 de septiembre de 2011. 
La reforma en materia de derechos humanos, como otras que se han verificado en años recientes, forma parte de un proceso de relevo paulatino de la CPEUM tras haber tropezado en varias ocasiones con la idea de sustituir la ley fundamental vigente por otra; es decir, el poder revisor ha optado por atender diversos asuntos de manera aislada y sucesiva. ${ }^{4}$ De este modo, la reforma constitucional que ahora tiene nuestra atención se ubica en lo que se denomina "reforma del Estado". 5

La doctrina no es unánime al respecto, pues algunos estudiosos sostienen que los procesos de reforma del Estado surgieron a finales de la década de los años setenta a partir del fenómeno mundial llamado "crisis fiscal del Estado". ${ }^{6}$ Otros, en cambio, manifiestan que tales procesos se gestaron en los años ochenta. ${ }^{7}$ De cualquier forma, uno de los factores que determinaron el inicio de estas reformas fue la crisis financiera, en particular de los países desarrollados. ${ }^{8}$ En nuestro país, los esfuerzos por la reforma del Estado iniciaron en la década de los años ochenta aunque de una manera incipiente, pero con el paso de los años dichos esfuerzos se fueron consolidando y fueron dando algunos frutos concretos.

Este trabajo tiene como objetivo hacer un análisis de las consecuencias que comporta la reciente reforma a la CPEUM para el sistema constitucional de los derechos humanos, principalmente en lo que se refiere a la dignidad humana. Para cumplir cabalmente con el dicho objetivo, el trabajo se

4 Cfr. García Ramírez, Sergio, "Hacia una nueva regulación constitucional sobre Derechos humanos (2009-2011)", Boletín Mexicano de Derecho Comparado, año XLIV, núm. 131, mayo-agosto de 2011, p. 818.

5 La reforma del Estado "suele traducirse en el trasiego de funciones y relaciones entre los poderosos, más que en la elevación en el nivel de vida, de felicidad y de esperanza de los ciudadanos". García Ramírez, Sergio, "La reforma del proceso penal. Riesgos y desafíos", en García Ramírez, Sergio e Islas de González Mariscal, Olga (coords.), Foro sobre Justicia Penal y Justicia para Adolescentes, México, UNAM, 2009, p. 161, y García Ramírez, Sergio, Poder Judicial y Ministerio Público, 3a ed., México, PorrúaUNAM, 2006, pp. 25-27. Ambos en ibídem, p. 31.

6 Carbonell, Miguel, La Constitución pendiente. Agenda minima de reformas constitucionales, México, UNAM, Instituto de Investigaciones Jurídicas 2002. En Peña Cid, Roberto y Ruiz Vargas, Dafne, "Hacia una reforma del Estado progresista: Los temas políticos", Revista de la Fundación por la Socialdemocracia de las Américas, núm. 9, julio-septiembre de 2007, s.p. Disponible en: http://www.fusda.org/Revista9-2ANTECEDENTES.pdf, consultada el 14 de septiembre de 2011.

7 Fleury, Sonia, "Reforma del Estado", Banco Interamericano de Desarrollo, diciembre de 2002. En: Peña Cid, Roberto y Ruiz Vargas, Dafne, op. cit., s.p.

8 Idem. 
divide en varias secciones: en la primera, se hace una breve reseña de los antecedentes más meritorios de la reforma constitucional con el propósito de develar los elementos que desde un inicio estuvieron presentes en la discusión, haciendo un estudio detallado de los mismos; en la segunda, se realiza un análisis de la enmienda constitucional en materia de derechos humanos, resaltando las novedades más relevantes que ha suscitado, e inmediatamente después nos referimos a la dignidad humana como eje rector de la praxis constitucional, para concluir con una serie de comentarios finales.

\section{ANTECEDENTES DE LA REFORMA CONSTITUCIONAL EN MATERIA DE DERECHOS HUMANOS}

En este apartado daremos cuenta del itinerario desplegado en el ámbito del derecho interno que traza los intentos por enmendar la CPEUM y ajustarla a las exigencias prácticas de los derechos humanos. Somos conscientes, no obstante, de que hay una pista internacional que igualmente contribuye a la configuración de esta reforma. Se trata de la ruta que históricamente ha seguido el Estado mexicano en la arena internacional desde una posición nacionalista y defensiva que anteponía la protección de la soberanía frente al régimen internacional de los derechos humanos, hasta una postulación internacionalista y cooperativa en esta misma materia. ${ }^{9}$

\section{Comisión de Estudios para la Reforma del Estado, junio de 2000}

En primer lugar, está la Comisión de Estudios para la Reforma del Estado (conformada el 14 de junio de 2000) que ordenó los temas de la agenda para la reforma del Estado en cinco rubros. El primero de ellos se refería a derechos humanos y libertades políticas.

En él se proponía: i) la supremacía y reconocimiento del carácter universal de los derechos humanos, ii) la plena autonomía de los órganos protectores de esos derechos y el carácter vinculatorio de sus recomen-

9 Cfr. Saltalamacchia, Natalia, y Covarrubias, Ana, "La dimensión internacional de la reforma de derechos humanos: antecedentes históricos", en Carbonell, M., y Salazar, P. (coords.), La reforma constitucional de derechos humanos: un nuevo paradigma, México, UNAM, Instituto de Investigaciones Jurídicas, 2011, p. 3. 
daciones, iii) combatir toda forma de discriminación racial, y iv) establecer el derecho a la función pública y a la participación ciudadana. ${ }^{10}$

\section{Iniciativa de la Cámara de Senadores, marzo de 2004}

En segundo lugar, está la iniciativa con proyecto de Decreto que reforma y adiciona diversas disposiciones de la CPEUM del 22 de marzo de 2004, presentada por el Senador Sánchez Carreño, del Grupo Parlamentario del Partido Revolucionario Institucional, a la Cámara de Senadores. ${ }^{11}$

La iniciativa de referencia, con base en distintos instrumentos internacionales y en antecedentes constitucionales domésticos, establece como sus propósitos fundamentales: $i$ ) redimensionar la jerarquía de los tratados internacionales en materia de derechos humanos ratificados por México conforme al artículo 133 constitucional, ii) profundizar la constitucionalización de los derechos humanos y iii) fortalecer el sistema de defensa de los mismos. La iniciativa propone, entre modificaciones y adiciones, lo siguiente:

a) Cambiar la denominación del capítulo I, título I para quedar como: "De los derechos humanos y las garantías individuales".

b) Modificar el primer y tercer párrafo del artículo 1o. para quedar, respectivamente:

En los Estados Unidos Mexicanos todo individuo gozará de los derechos humanos que reconocen esta Constitución y los tratados internacionales firmados y ratificados, y de las garantías que otorga la misma, las cuales no podrán restringirse ni suspenderse, sino en los casos y con las condiciones que ella misma establece.

Queda prohibida toda discriminación a cualquier individuo o grupo motivada por origen étnico o nacional, el género, la edad, las capacidades diferentes, la condición social, las condiciones de salud, la religión, las opiniones, las preferencias, el estado civil o cualquier otra que atente contra la dignidad humana y tenga por objeto anular o menoscabar los derechos y libertades de las personas.

10 Cámara de Diputados, Perspectiva sobre la reforma del Estado, Centro de Estudios Sociales y de Opinión Pública, 2005. Disponible en http://www.diputados.gob.mx/cesop/ doctos/REFORMA\% 20DEL\%20ESTADO. Pdf, consultada el 14 de septiembre de 2011.

11 Gaceta del Senado, Segundo Periodo Ordinario, núm. 39, 23 de marzo de 2004. Disponible en: http://www.senado.gob. $m x /$ index.php? ver $=s p \& m n=2 \& s m=2 \& i d=1458 \&$ $l g=59$, consultada el 14 de septiembre de 2011 . 
c) Modificar la fracción I del artículo 103 para quedar:

Los tribunales de la Federación resolverán toda controversia que se suscite:

I. Por las leyes o actos de la autoridad que violen los derechos humanos y sus garantías reconocidos y amparados por esta Constitución y por los tratados internacionales, como son, la Declaración Universal de los derechos humanos; Pacto Internacional de Derechos Civiles y Políticos; Pacto Internacional de Derechos Económicos, Sociales y Culturales; Declaración Americana de los Derechos y Deberes del Hombre; Convención Americana sobre derechos humanos "Pacto de San José de Costa Rica" y, firmados y ratificados de acuerdo con la misma.

d) Modificar el artículo 133 para quedar:

Esta Constitución, los tratados internacionales que estén de acuerdo con la misma, celebrados y que se celebren por el Presidente de la República con la aprobación del Senado y; las leyes del Congreso de la Unión que emanen de ella, en ese orden serán la Ley Suprema de toda la Unión.

Los jueces y demás autoridades de las entidades federativas y de los municipios se arreglarán a dicha Constitución, tratados internacionales, y leyes, a pesar de las disposiciones en contrario que pueda haber en las Constituciones o leyes de los Estados.

\section{Iniciativa presentada por el Ejecutivo a la Cámara de Senadores, abril de 2004}

En tercer lugar, está la iniciativa de Decreto que reforma diversos artículos de la CPEUM en materia de derechos humanos, del 27 de abril de 2004, presentada por el Ejecutivo Federal a la Cámara de Senadores que integra, entre otras, las conclusiones obtenidas de los trabajos de la Comisión referida anteriormente. ${ }^{12}$

Esa iniciativa tenía como propósito fortalecer el reconocimiento y protección de los derechos humanos y, al mismo tiempo, consolidar cabalmente las instituciones democráticas. En la exposición de motivos admite que nuestro país ha sido parte en declaraciones y tratados internacionales que no sólo reconocen los principios de la Declaración Universal de Derechos Humanos de 1948, sino que amplían los mismos

12 Gaceta del Senado, Segundo Receso Comisión Permanente, núm. 1, 5 de mayo de 2004. Disponible en: http://www.senado.gob. $m x /$ index.php? ver $=s p \& m n=2 \& s m=2 \& i d=$ $2126 \& \lg =59$. 
para dar mayor protección a la persona humana. Se sostiene que desde el surgimiento de la Organización de las Naciones Unidas, México ha firmado y ratificado prácticamente todos los tratados internacionales de derechos humanos, así como también ha apoyado todas las declaraciones en esa materia. Consecuentemente, los derechos humanos reconocidos y protegidos en el ámbito internacional se han integrado en el sistema jurídico mexicano mediante la propia CPEUM, o bien por medio de otras disposiciones del orden jurídico interno. No obstante lo anterior, advierte un rezago en la materia.

Señala que la CPEUM al no reconocer de manera expresa y categórica los derechos humanos conlleva, por una parte, que la autoridad no los considere como criterio orientador de su actuación y por otra, que los derechos humanos incorporados mediante la firma de tratados internacionales tengan una protección limitada.

Entre otros, la iniciativa en comento propone: en primer término, reformar la denominación del capítulo I, título I a modo que se titule "De los derechos fundamentales" y así agrupar, armónicamente y sin necesidad de discusiones doctrinarias, los derechos humanos y las garantías individuales. En segundo término, añadir un segundo párrafo al artículo 1o. con el siguiente enunciado: "Los derechos humanos son reconocidos por esta Constitución y su protección se realizará en los términos establecidos en la misma". Y, en tercer término, reformar el artículo 103 fracción I para adicionar la frase: "o los derechos humanos".

Aunque las dos iniciativas que se han citado no prosperaron en su momento, contenían varios aspectos medulares de los derechos humanos que hoy vemos de algún modo materializados en la CPEUM.

\section{Dictamen de la Cámara de Diputados, abril de 2009}

En cuarto lugar, está el Dictamen de las Comisiones Unidas de Puntos Constitucionales y Derechos Humanos de la Cámara de Diputados con proyecto de Decreto que reforma diversas disposiciones de la CPEUM en materia de derechos humanos, del 23 de abril de $2009 .{ }^{13}$

13 Gaceta Parlamentaria, año XII, núm. 2743-XVI, 23 de abril de 2009. Disponible en: http://gaceta.diputados.gob.mx/Gaceta/60/2009/abr/20090423-XVI.pdf, consultada el 24 de septiembre de 2011. 
En ese dictamen se analizan las 33 iniciativas presentadas en el seno de la Cámara de Diputados del 21 de noviembre de 2006 al 27 de agosto de 2008, señalando que pretende dotar a la CPEUM de los elementos y mecanismos necesarios para garantizar la máxima protección de los derechos humanos, procurando dar cumplimiento a las obligaciones internacionales que en esta materia ha reconocido nuestro país con la firma y ratificación de diversos tratados internacionales e incorporando un régimen más amplio de protección de los mismos. Se sostiene, además, que el Congreso de la Unión debe aprovechar la oportunidad histórica para otorgar a los derechos humanos un lugar preferente en la CPEUM, proceso que por más de una década ha esperanzado a que se logre con amplia participación de la sociedad civil.

La propuesta aprobada por la Cámara de Diputados incluía, entre otras reformas constitucionales, la modificación a la denominación del Capítulo I, Título I para quedar como: "De los derechos humanos", y la reforma al artículo 1o. según el siguiente texto:

En los Estados Unidos Mexicanos todas las personas gozarán de los derechos humanos reconocidos por esta Constitución y en los tratados internacionales de derechos humanos ratificados por el Estado mexicano, los cuales no podrán restringirse ni suspenderse, sino en los casos y con las condiciones que la misma Constitución establece. Las garantías para su protección serán las que establezcan la Constitución y las leyes que de ella emanen.

Tratándose de normas de derechos humanos, éstas se interpretarán de conformidad con esta Constitución y con los tratados internacionales de derechos humanos de los que México, sea parte. En su aplicación, bajo el principio de no contradicción con esta Constitución, se observaran aquellas que resulten más favorables a los derechos de las personas.

Todas las autoridades, en el ámbito de sus competencias, tienen la obligación de promover, respetar, proteger y garantizar los derechos humanos de conformidad con los principios de universalidad, interdependencia, indivisibilidad y progresividad. En consecuencia, el Estado deberá prevenir, investigar y sancionar las violaciones a los derechos humanos.

(...)

Lo anterior en virtud de que los derechos humanos al ser inherentes a la dignidad de la persona deben ser reconocidos por el Estado por medio de sus leyes. Su vigencia, protección, defensa, promoción, educación y vigi- 
lancia son responsabilidad del Estado la cual se ha reforzado con la firma y ratificación de diversos tratados internacionales en esa materia.

Además, se sustituye el término "individuo" por "persona" a modo de evitar limitaciones y dotar de una connotación jurídica más apropiada al reconocimiento de los derechos humanos.

Por otra parte, se incorpora el principio pro personae que ordena, por un lado, una aplicación más amplia y una interpretación más extensa de la norma constitucional cuando trata de reconocer unos derechos protegidos $\mathrm{y}$; por otro, una aplicación y una interpretación más restringida cuando se trata de establecer límites al ejercicio de los derechos o su suspensión extraordinaria.

Finalmente, se introducen diversas obligaciones que el Estado debe asumir frente a la violación de los derechos humanos, tales como: las de prevención, investigación y sanción de los actos violatorios de esos derechos.

La Minuta correspondiente fue turnada a las Comisiones Unidas de Puntos Constitucionales y de Estudios Jurídicos de la Cámara de Senadores el 28 de abril de 2009 para su análisis, estudio y elaboración del dictamen.

\section{Iniciativa de la Cámara de Senadores, febrero de 2010}

En quinto lugar, está la iniciativa con proyecto de Decreto por el que se reforman, adicionan y derogan diversas disposiciones de la CPEUM en materia de reforma del Estado, presentada a la Cámara de Senadores el 23 de febrero de 2010 que, entre otros, propone la reforma del artículo 29 que regula lo relativo a la suspensión de garantías. ${ }^{14}$

Esa iniciativa propone, por ejemplo, eliminar la facultad de la Comisión Permanente para aprobar la suspensión de garantías aludiendo que debe ser el Congreso de la Unión el órgano que ejerza esta facultad constitucional. También incluye la propuesta de que la Suprema Corte de Justicia revise en proceso sumarísimo la constitucionalidad de los decretos que emita el Ejecutivo durante la suspensión de garantías. Este antecedente será analizado más adelante en la parte conducente.

14 Gaceta del Senado, Segundo Periodo Ordinario, núm. 88, 23 de febrero de 2010. Disponible en: http://www.senado.gob.mx/sgsp/gaceta/61/1/2010-02-231/assets/documentos/disposiciones_CPEUM.pdf, consultada el 14 de mayo de 2012. 
6. Dictamen de la Cámara de Senadores, abril de 2010

En sexto lugar, está el Dictamen de las Comisiones Unidas de Puntos Constitucionales y de Estudios Legislativos, con Opinión de la Comisión de Reforma del Estado de la Cámara de Senadores, respecto a la Minuta relacionada en el antecedente cuarto, de fecha 7 de abril de $2010 .{ }^{15}$

Un año después de que fue enviado el documento por la Cámara de Diputados, el Senado elaboró un dictamen en el que examinó la Minuta de la Cámara de Origen junto con 14 iniciativas presentadas en el seno de la Cámara de Senadores. Los puntos más relevantes del dictamen en relación con el tema que nos ocupa son:

1. En cuanto a la denominación del capítulo I, título I, el dictamen aludido considera pertinente el cambio como lo plantea la Cámara de Origen; sin embargo, se estima conveniente que en tal denominación también sean consideradas las garantías. De este modo, se propone que la denominación sea: "De los derechos humanos y sus garantías".

2. En cuanto al artículo 1o., se propone la siguiente redacción:

En los Estados Unidos Mexicanos todas las personas gozarán de los derechos humanos reconocidos en esta Constitución y en los tratados internacionales sobre derechos humanos de los que el Estado Mexicano sea parte, así como de las garantías para su protección, los cuales no podrán restringirse ni suspenderse, salvo en los casos y bajo las condiciones que esta Constitución establece.

Las normas relativas a los derechos humanos se interpretarán de conformidad con esta Constitución y con los tratados internacionales sobre derechos humanos antes señalados.

Todas las autoridades, en el ámbito de sus competencias, tienen la obligación de promover, respetar, proteger y garantizar los derechos humanos de conformidad con los principios de universalidad, interdependencia, indivisibilidad y progresividad. En consecuencia, el Estado deberá prevenir, investigar, sancionar y reparar las violaciones a los derechos humanos, en los términos que establezca la ley.

(...)

15 Gaceta del Senado, Segundo Periodo Ordinario, núm. 113, 7 de abril de 2010. Disponible en: http://www.senado.gob.mx/sgsp/gaceta/61/1/2010-04-07- assets/documentos/derechos_humanos.pdf, consultada el 14 de mayo de 2012. 
Lo anterior con fundamento en los siguientes razonamientos:

a) En el dictamen se menciona que es necesario un amplio reconocimiento de los derechos humanos dándoles carácter constitucional a todos y por ello deben considerarse incluidos tanto los que se encuentran expresamente reconocidos en el texto constitucional como los consagrados en tratados internacionales de los que México sea parte. Esto con el objeto de no crear derechos de primera y segunda categoría según estén o no en la CPEUM.

b) También se estima conveniente explicitar que la no restricción ni suspensión se refiere tanto a los derechos humanos como a sus garantías. Por esta razón, se sostiene que el artículo 29 necesita una clara adecuación para ubicarlo a nivel de los postulados del constitucionalismo moderno y de los tratados internacionales en materia de derechos humanos firmados y ratificados por México.

c) Se propone adoptar el principio de "interpretación conforme" que permite una aplicación subsidiaria del ordenamiento internacional con el objeto de llenar las lagunas existentes sin que esto signifique, en ningún momento, la derogación o no aplicación de una norma de derecho interno. El principio de subsidiariedad elimina criterios de supra-subordinación y hace posible que el intérprete de la Constitución pueda acudir a normas de derechos humanos consagradas en los tratados internacionales de los que México sea parte para ofrecer una mayor protección a las personas.

d) Coincide con la Minuta de la Cámara de Diputados en que es necesario un nuevo tercer párrafo del artículo 1o. que contenga la obligación de las autoridades de promover, respetar, proteger y garantizar los derechos humanos de conformidad con los principios de universalidad, interdependencia, indivisibilidad y progresividad.

e) En la parte final del tercer párrafo del artículo 1o. propuesto por la Cámara de Origen se considera oportuno añadir la obligación del Estado de reparar las violaciones a los derechos humanos.

3. En cuanto al primer y segundo párrafos del artículo 29, se propone la siguiente redacción:

En casos de invasión, perturbación grave a la paz pública, o de cualquier otro que ponga a la sociedad... 
En ningún caso podrán restringirse ni suspenderse el ejercicio de los derechos a la no discriminación...

En los casos de invasión, perturbación grave de la paz pública, o de cualquier otro que ponga a la sociedad en grave peligro o conflicto, solamente el Presidente de los Estados Unidos Mexicanos, de acuerdo con los titulares de las Secretarías de Estado y la Procuraduría General de la República y con la aprobación del Congreso de la Unión podrá restringir o suspender en todo el país o en lugar determinado el ejercicio de los derechos y las garantías que fuesen obstáculo para hacer frente, rápida y fácilmente a la situación; pero deberá hacerlo por un tiempo limitado, por medio de prevenciones generales y sin que la restricción o suspensión se contraiga a determinada persona. Si la restricción o suspensión tuviese lugar hallándose el Congreso reunido, éste concederá las autorizaciones que estime necesarias para que el Ejecutivo haga frente a la situación; pero si se verificase en tiempo de receso, se convocará sin demora al Congreso para que las acuerde.

$$
\text { (...) }
$$

Para esta reforma se argumenta lo siguiente:

Se juzga imperioso relacionar y armonizar la propuesta de reforma del artículo 1o. con la iniciativa de reforma constitucional en materia de reforma del Estado relacionada en el antecedente quinto de este trabajo.

Cabe decir que en la iniciativa a la que se hace referencia, se enlistan varios derechos que no podrán restringirse ni suspenderse, entre los cuales no figura el derecho a la vida. Ese derecho, junto con otros - con base en lo que se llama "núcleo duro", es decir, el conjunto de derechos de carácter insuspendible - , fue incorporado en el dictamen del Senado.

Además, se reconoce expresamente, por un lado, que el derecho a la vida cobra especial relevancia en el escenario de reformas en materia de derechos humanos y; por otro, que el listado de derechos de carácter insuspendible contenidos en el artículo 29 no es taxativa; por tanto, no es inalterable en razón de que existen otros derechos que pueden quedar protegidos de restricción o suspensión en su ejercicio.

En la sesión del 8 de abril de 2010 la Cámara de Senadores emite la Minuta correspondiente y la envía a la Cámara de Diputados conforme a lo dispuesto por el artículo 72 fracción e) de la CPEUM. 


\section{Dictamen de la Cámara de Diputados, diciembre de 2010}

En séptimo y último lugar, está el Dictamen de las Comisiones Unidas de Puntos Constitucionales y Derechos Humanos de la Cámara de Diputados, del 13 de diciembre de 2010. ${ }^{16}$

En ese dictamen se define a los derechos humanos como el conjunto de prerrogativas inherentes a la naturaleza de la persona, cuya realización efectiva resulta indispensable para el desarrollo integral del individuo que vive en una sociedad jurídicamente organizada. Estos, además, deben ser reconocidos y garantizados por el Estado. Los derechos humanos son universales, permanentes, progresivos y preexistentes al Estado o norma fundamental.

En tanto que las garantías individuales son derechos públicos subjetivos que dan a sus titulares la potestad de exigirlos jurídicamente a través de los instrumentos jurídicos consignados en la Constitución o norma fundamental.

Con base en lo anterior, las garantías individuales son los límites de la actuación del poder público consagrados de manera precisa en un texto constitucional; por su parte, los derechos humanos son anteriores y superan el poder público y, aunque no estén consagrados en una Constitución, el Estado se constriñe a reconocerlos, respetarlos y protegerlos.

En este sentido, el dictamen refiere que la Constitución de 1857 tenía una fuerte carga "iusnaturalista"; en cambio, la Constitución de 1917 es de connotación fundamentalmente "iuspositivista".

Por tanto, el dictamen coincide con la postura de la minuta del Senado en cuanto a reconocer constitucionalmente los derechos humanos de las personas y establecer las garantías para lograr la efectividad de su protección.

No obstante, modifica la redacción del artículo 1o. propuesta por el Senado en dos sentidos. Según el primero, la alusión a tratados internacionales no debe ser sólo en materia de derechos humanos, pues ello sería tanto como limitarlos. Incorporar en la CPEUM la aplicación de instrumentos internacionales que otorguen mayor y mejor protección a los derechos humanos nunca será excesivo. $\mathrm{Y}$, de acuerdo al segundo, es necesario explicitar la prohibición de toda discriminación por motivo de las preferencias sexuales de las personas. Según lo que se sostiene en el dictamen, no considerar a las

${ }^{16}$ Gaceta Parlamentaria, año XIV, número 3162-IV, 5 de diciembre de 2010, http:// gaceta.diputados.gob.mx/Gaceta/61/2010/dic/20101215-IV.html\#DictamenesaD, consultada el 24 de septiembre de 2011. 
preferencias sexuales dentro de las formas de la discriminación, sería negar los derechos inalienables que tenemos todos los seres humanos.

En cuanto al artículo 29, en el dictamen se advierte que debe suprimirse la expresión "sobre derechos humanos" para que guarde armonía con lo propuesto para el artículo 1o.. También se ofrecen algunas consideraciones para mantener la facultad del la Comisión Permanente para aprobar la restricción o suspensión de los derechos y de las garantías, así como cambiar la expresión genérica "libertad religiosa" por "profesar creencia religiosa alguna" con el propósito de que sí puedan ser restringidos o suspendidos los actos religiosos de culto público.

Por lo que hace al derecho a la vida, particularmente a su protección desde el momento de la concepción, en el dictamen se sostiene expresamente que su contenido y alcances permanecen tal y como se encuentran reconocidos en la CPEUM y en los tratados internacionales signados por México con las reservas y declaraciones interpretativas. En consecuencia, su alusión como parte de los derechos que no pueden restringirse ni suspenderse solamente atiende a una enunciación formal por lo que no se afecta o modifica su contenido.

De este modo, se propone el siguiente texto para el artículo 1o. que es el que se publicó en el Diario Oficial de la Federación el 10 de junio de 2011.

En los Estados Unidos Mexicanos todas las personas gozarán de los derechos humanos reconocidos en esta Constitución y en los tratados internacionales de los que el Estado Mexicano sea parte, así como de las garantías para su protección, cuyo ejercicio no podrá restringirse ni suspenderse, salvo en los casos y bajo las condiciones que esta Constitución establece.

Las normas relativas a los derechos humanos se interpretarán de conformidad con esta Constitución y con los tratados internacionales de la materia favoreciendo en todo tiempo a las personas la protección más amplia.

Todas las autoridades, en el ámbito de sus competencias, tienen la obligación de promover, respetar, proteger y garantizar los derechos humanos de conformidad con los principios de universalidad, interdependencia, indivisibilidad y progresividad. En consecuencia, el Estado deberá prevenir, investigar, sancionar y reparar las violaciones a los derechos humanos, en los términos que establezca la ley.

(...)

Queda prohibida toda discriminación motivada por origen étnico o nacional, el género, la edad, las discapacidades, la condición social, las con- 
diciones de salud, la religión, las opiniones, las preferencias sexuales, el estado civil o cualquier otra que atente contra la dignidad humana y tenga por objeto anular o menoscabar los derechos y libertades de las personas.

De igual forma, se propone el siguiente texto para el artículo 29 que es el que se publicó en el Diario Oficial de la Federación el 10 de junio de 2011.

En los casos de invasión, perturbación grave de la paz pública, o de cualquier otro que ponga a la sociedad en grave peligro o conflicto, solamente el Presidente de los Estados Unidos Mexicanos, de acuerdo con los titulares de las Secretarías de Estado y la Procuraduría General de la República y con la aprobación del Congreso de la Unión o de la Comisión Permanente cuando aquel no estuviere reunido, podrá restringir o suspender en todo el país o en lugar determinado el ejercicio de los derechos y las garantías que fuesen obstáculo para hacer frente, rápida y fácilmente a la situación...

${ }^{\mathrm{E}} \mathrm{n}$ los decretos que se expidan, no podrá restringirse ni suspenderse el ejercicio de los derechos a la no discriminación, al reconocimiento de la personalidad jurídica, a la vida, a la integridad personal, a la protección a la familia, al nombre, a la nacionalidad; los derechos de la niñez; los derechos políticos; las libertades de pensamiento, conciencia y de profesar creencia religiosa alguna...

(...)

\author{
III. LA REFORMA CONSTITUCIONAL EN MATERIA \\ DE DERECHOS HUMANOS DEL 10 DE JUNIO DE 2011: \\ CLAVES DEL NUEVO PARADIGMA JURÍDICO
}

En los puntos que siguen daremos cuenta de algunos de los cambios más relevantes que supone la reforma constitucional en materia de derechos humanos que entró en vigor el pasado mes de junio de 2011, y ello mediante una somera descripción junto algún comentario general sobre su contenido.

\title{
1. Introducción del concepto de derechos humanos en el texto constitucional
}

La incorporación del concepto derechos humanos en el texto constitucional se da en varios artículos modificados a través de la reforma; no obstante, cobran particular relevancia dos lugares donde se emplea esa nomenclatura 
por múltiples razones de naturaleza teórica, filosófica, simbólica y práctica, a saber, en primer lugar la denominación del capítulo I del título primero que en adelante es: "De los derechos humanos y sus garantías", y en segundo el primer párrafo del artículo 1o., que a la letra dice: “Artículo 1. En los Estados Unidos Mexicanos todas las personas gozarán de los derechos humanos reconocidos en esta Constitución y en los tratados internacionales de los que el Estado Mexicano sea parte...".

Frente a varias posibilidades conceptuales (derechos públicos subjetivos, derechos fundamentales, derechos naturales, etcétera), a nuestro juicio, el término derechos humanos es el más adecuado, en comparación con los mencionados para referirnos a esta realidad: las ventajas semánticas se manifiestan, ante todo, porque su valor práctico se proyecta de manera amplia, de tal forma que no se restringe al campo estrictamente jurídico, y mucho menos a la relación gobernante-gobernado, sino que es un término propicio para reconocer que las obligaciones y los deberes vinculados a los derechos humanos no se limitan a los de carácter estatal, sino que nos implica a todos. Por otro lado, el discurso que emplea el término derechos humanos es el espacio propicio para acometer la ardua tarea de resolver las dudas teóricas acerca de quién es persona y proporciona razones para extender el significado jurídico de este concepto a toda realidad humana, y en esta medida se limita el carácter arbitrario que en muchas ocasiones se manifiesta en relación con estos temas.

\section{Distinción entre derechos humanos y sus garantías}

Tanto en la denominación del capítulo I del título primero, como en el mismo artículo 1 se realiza una clara distinción entre los derechos humanos y las vías, de naturaleza jurídica, a través de los cuales se garantiza su respeto. La distinción tiene sentido en la medida en que, con la reforma, se aclara la naturaleza de cada uno de los elementos implicados en ella. Por un lado, los derechos son reconocidos por el Estado mexicano: se trata pues de realidades jurídicas cuya validez no descansa en la voluntad de quienes tienen la facultad de definir el contenido del derecho positivo (fuentes sociales); mientras que las garantías son instrumentadas y en cierta medida concedidas o generadas para brindar a los titulares de aquellos, los medios para exigir su respeto y el cumplimiento de las obligaciones asociadas. Así las cosas, primero son los derechos humanos, incluyendo los bienes y las 
obligaciones que forman parte de su objeto, y en segundo lugar la realidad técnico-jurídica, es decir, los medios para actualizar los referidos bienes y obligaciones; por ejemplo, el juicio de amparo, por el que el titular de un derecho reclama el respeto del mismo frente a las violaciones de las que sea objeto por parte de una autoridad estatal.

\section{Descripción especifica de las obligaciones que asume el Estado mexicano frente a los derechos humanos}

Una de las novedades más importantes que incorpora la reforma constitucional en materia de derechos humanos es la especificación explícita de las obligaciones que asume el Estado mexicano frente a ellos. El párrafo tercero del artículo 1 es el locus en el que, principalmente, se lleva a cabo esta descripción:

Artículo 1o. (...) Todas las autoridades, en el ámbito de sus competencias, tienen la obligación de promover, respetar, proteger y garantizar los derechos humanos (...). En consecuencia, el Estado deberá prevenir, investigar, sancionar y reparar las violaciones a los derechos humanos, en los términos que establezca la ley.

Como puede observarse, la actividad del Estado en relación con los derechos humanos se concreta en varios verbos. Promover: lo cual supondrá, entre otras cosas la postulación de políticas públicas, sobre todo en materia educativa, que contribuyan al conocimiento del significado práctico de los derechos humanos. La enmienda al artículo tercero de la CPEUM, incluida en este mismo proceso de reforma, se alinea perfectamente con tal exigencia. En efecto, según el referido numeral, una de las finalidades explícitamente reconocidas de la educación que imparta el Estado será el fomento del respeto de los derechos humanos, así como el desarrollo de una conciencia habilitada para la experiencia de la solidaridad y la justicia. ${ }^{17}$

Con ello, la reforma constitucional que venimos comentando hace suya la interpretación de la universalidad de los derechos humanos no sólo como un rasgo formal, sino como una meta social cuya expresión más acabada sería el auténtico arraigo de una cultura de los derechos huma-

${ }^{17}$ Cfr., artículo 3o. de la CPEUM. 
nos, esto es, aquella situación en la que su contenido es comprendido por la población, y a partir de tal conocimiento los respeta y los exige. ${ }^{18}$

Respetar: atendiendo a la Observación General 31 del Comité de Derechos Humanos, esta obligación significa que los Estados deben abstenerse de violar todos y cada uno de los derechos humanos reconocidos, añadiendo que cualquier restricción en el goce y ejercicio de los mismos deberá realizarse de conformidad con disposiciones legales específicas y aplicables a cada caso.

Proteger: en concreto, serán aquellas medidas legislativas, incluida la incorporación del contenido del derecho internacional de los derechos humanos a la legislación interna o a sus normas de interpretación; las medidas administrativas que pueden consistir en el establecimiento de políticas públicas, financieras, educativas, expedición de reglamentos, etcétera, y las medidas jurisdiccionales que, al conocer de litigios cuyo objeto sea un derecho humano, consigan su desarrollo. Los derechos cuyo contenido normativo es de aplicación inmediata y los de aplicación progresiva necesitan medidas adecuadas para que se puedan respetar, proteger y realizar. Asimismo, el derecho a los procesos judiciales justos necesita la asignación de recursos públicos, planes de acción y políticas públicas encaminados a la protección de ese derecho.

Garantizar: con este concepto el derecho internacional entiende tanto al deber de respetar como a la obligación de hacer, al asegurar la aplicación de los contenidos normativos de los derechos a todos los individuos que se encuentren en el territorio de un Estado y, por tanto, sometidos a su jurisdicción. ${ }^{19}$ Desde el punto de vista teórico, estas garantías se han

18 Cabe decir que una cultura de los derechos humanos, impulsada por la educación pública, ayudaría a configurar un amplio conjunto de objetos artísticos que hacen más asequible el lenguaje de los derechos. Como lo explica Vicente Bellver: "Para que los derechos humanos estén garantizados, el Estado tiene que proporcionar los medios adecuados: leyes en los que se proclamen, organismos de la administración que los hagan efectivos, y tribunales a los que acudir exigiendo justicia. (...) Pero todos esos instrumentos, siendo necesarios, no son suficientes. Una comunidad no verá plenamente garantizados sus derechos si no cuenta con una cultura ciudadana de los derechos. Vicente Bellver, "Los derechos humanos ¿quién vigila al vigilante?”, Pérez Adán, José, Cine y sociedad. Prácticas de ciencias sociales, Madrid, EIUNSA, 2004, p. 166.

19 Véase Comité de Derechos Humanos, Observación general 31, "La índole de la obligación jurídica general impuesta”, 80 periodo de sesiones, U.N. Doc. HRI/GEN/1/ Rev.7 at 225 (2004), párrafo 3. 
clasificado como primarias y secundarias. ${ }^{20}$ Las primeras apuntan al establecimiento de obligaciones y prohibiciones explícitas que se dirijan a la realización efectiva del núcleo normativo del derecho en cuestión. Las segundas constituyen las obligaciones de sancionar o reparar las violaciones a los derechos; con mayor precisión: identificar y sancionar a los responsables de los actos con los que se vulnera el derecho; restaurar y reparar el derecho violado, incluido el deber de prevención, con medidas jurídicas, políticas, administrativas y culturales para evitar casos futuros, $\mathrm{y}$, respecto a los actos de particulares, establecer un sistema de prevención, investigación y sanción en caso de que éstos sean los que vulneren los derechos humanos.

Cobra particular interés la obligación del Estado mexicano de reparar las violaciones que se lleven a cabo sobre los derechos humanos, previa investigación. El artículo segundo transitorio del Decreto establece que el Congreso de la Unión deberá legislar específicamente sobre los alcances de esta obligación en un plazo no mayor de un año contado a partir de la fecha de entrada en vigor del mismo. Será entonces cuando se conozcan los pormenores jurídicos de la obligación que asume el Estado mexicano de reparar a las personas cuando sus autoridades y servidores públicos realicen actos que vulneren sus derechos. Por lo pronto, es posible acudir a la práctica internacional en materia de reparación por violaciones de derechos humanos, en concreto a la que ha llevado a cabo la Corte Interamericana de Derechos Humanos interpretando el principio de restitutio in integrum, el cual implica: 1. restitución y/o rehabilitación del derecho violado; 2. indemnización material y moral justa, y 3 . reparar el daño provocado por la violación. La primera consecuencia de la reparación es restablecer el derecho violado tanto de hecho como de derecho; es decir, no sólo es un devolver el ejercicio de un derecho, sino que también debe reponer la situación -jurídica, económica, de seguridad social, personal, de salud, etcétera- que disfrutaba la víctima antes de sufrir una violación a sus derechos. Para ello, el demandado deberá no sólo devolver el derecho conculcado, sino también sufragar los gastos médicos, transporte, etcétera, para regresar la situación a su estado original. En caso de que esto no sea posible, se determinan reparaciones sustitutivas: indemnización y reparación del daño. Los montos para reparar el daño se calculan principalmente en función de la pérdida

20 Ferrajoli, Luigi, Derechos y garantías. La ley del más débil, Madrid, Trotta, 2002, pp. 59-61. 
de ingresos económicos futuros (lucro cesante), la afectación patrimonial derivada directa e inmediatamente de la violación (daño emergente) y el monto equitativo por el daño moral sufrido con ocasión de los hechos.

\section{Identificación de los principios que rigen la materia} de derechos humanos

Los párrafos segundo y tercero del nuevo artículo 1 constitucional explicitan algunos de los que, desde la perspectiva teórica, se denominan rasgos esenciales de los derechos humanos, y desde una aproximación práctica serían los principios que informan la labor de sus intérpretes. Se trata de la universalidad, interdependencia, indivisibilidad, progresividad, así como el principio pro personae. El principio de universalidad puede comprenderse en dos sentidos: como punto de partida y llegada en la praxis de los derechos humanos. Respecto del primer sentido, la universalidad de los derechos quiere decir que el único requisito necesario para la titularidad de los mismos es la condición de pertenecer al género humano, lo que podría denominarse universalidad en el título: "la garantía de tales derechos es completamente independiente de las situaciones y circunstancias en que los seres humanos vivan y de las posiciones jurídicas que eventualmente desempeñen". ${ }^{21}$ Por su parte, la universalidad como punto de llegada comprende, por un lado, la expansión de la cultura de los derechos humanos a toda sociedad; es decir, el conjunto de objetos producidos por mujeres y hombres, donde estos derechos tengan particular protagonismo; por ejemplo, donde sean la razón de ser de diversas instituciones de carácter público, como los tribunales especializados en resolver casos donde se reclama un derecho humano, o bien organizaciones de la sociedad civil que los promueven; asimismo, la cultura de los derechos humanos se manifiesta donde las personas comprenden su significado, y en esta medida exigen sus derechos, y respetan y promueven los derechos de los demás. La universalidad de los derechos como meta significa también la transformación de la sociedad para eliminar toda forma de discriminación y marginación. Jesús Ballesteros explica que "el marginado es un ser (humano) que no logra ver reconocidos plenamente

21 Martínez-Pujalte, Antonio-Luis, "La universalidad de los derechos humanos y la noción constitucional de persona”, en Ballesteros, J. y Fernández, E. (coords.), Justicia, solidaridad, paz. Estudios en Homenaje al Profesor José María Rojo Sanz, Valencia, Universidad de Valencia, 1995, p. 264. 
sus derechos fundamentales y, por tanto, satisfechas sus necesidades básicas, que aquéllos salvaguardan". ${ }^{22}$

Por otro lado, la interdependencia es el rasgo que vincula el contenido y exigencias de todos los derechos humanos, de tal manera que podemos pensar en ellos como un bloque de bienes en favor de la persona. A partir de este principio, se entiende que la vigencia de unos derechos es precondición para la plena realización de los otros, de forma tal que la violación o desconocimiento de alguno de ellos termina por afectar al conjunto. Muy próximo a este principio se sitúa el carácter indivisible de los derechos, porque a partir de este aspecto se concluye que entre los derechos no es viable la configuración de una jerarquía que por ejemplo, desde una perspectiva práctica autorice el sacrificio de un derecho o el menoscabo de otro, como costo del respeto de un tercero.

El principio de progresividad da sentido a las obligaciones del Estado mexicano para incrementar paulatinamente el desarrollo de políticas públicas que tiendan a una mayor protección, respeto y garantía de los derechos humanos; vinculado a lo anterior se encuentra el principio de no regresividad o irreversibilidad, que consiste en la imposibilidad de suprimir la condición de un derecho humano, una vez que el Estado lo ha reconocido mediante algún instrumento jurídico. La irreversibilidad de los derechos humanos resulta de particular relevancia en el ámbito del derecho internacional, sobre todo frente a la denuncia de algún tratado o convención en el que se ha reconocido un derecho humano; en este caso, la denuncia no afecta las obligaciones contraídas por el Estado denunciante en relación con los derechos reconocidos en el tratado en cuestión. El renovado contenido del artículo 15 de la CPEUM recoge este principio al declarar la imposibilidad de suprimir la condición de un derecho humano una vez que el Estado lo ha reconocido mediante algún instrumento jurídico ad hoc. Tomemos en consideración el texto del mencionado artículo: "No se autoriza la celebración de tratados (...) en virtud de los que se alteren los derechos humanos reconocidos por esta Constitución y en los tratados internacionales de los que el Estado Mexicano sea parte".

Tal vez una de las inclusiones más relevantes que se pueden observar en el Decreto tiene que ver con el denominado principio pro personae (o también principio pro homine). Su reconocimiento se realiza en el párrafo

22 Ballesteros, Jesús, Postmodernidad: de cadencia o resistencia, Madrid, Tecnos, 2000, pp. 43 y 44 . 
segundo del artículo primero que a la letra dice: "Las normas relativas a los derechos humanos se interpretarán (...) favoreciendo en todo tiempo a las personas la protección más amplia". Este principio indica que el intérprete del derecho ha de seleccionar y aplicar la norma que en cada caso resulte más favorable para la persona, cualquiera sea la fuente que la suministre, ya sea interna o internacional. Adicionalmente, este criterio hermenéutico obliga a acudir a la norma más amplia, o interpretación más extensiva, cuando se trate de reconocer derechos protegidos e, inversamente, a la norma o a la interpretación más restringida cuando se trata de establecer límites permanentes al ejercicio de los derechos o su suspensión extraordinaria.

\section{Un catálogo constitucional de derechos humanos}

En el Decreto se consignan importantes cambios en el artículo 29 constitucional, aunque mantiene la vocación previa a la reforma, es decir, la definición de las condiciones jurídicas en las que será lícito limitar el ejercicio de derechos (antes suspensión de garantías individuales). La novedad a la que queremos hacer referencia es el listado de un conjunto de derechos humanos explícitamente reconocidos por la CPEUM, mismos que se mantendrán al margen de las restricciones y suspensiones temporales para atender adecuadamente situaciones de emergencia. Tales derechos son: a la no discriminación, al reconocimiento de la personalidad jurídica, a la vida, a la integridad personal, a la protección a la familia, al nombre, a la nacionalidad; los derechos de la niñez; los derechos políticos; las libertades de pensamiento, conciencia y de profesar creencia religiosa alguna; el principio de legalidad y retroactividad; la prohibición de la pena de muerte; la prohibición de la esclavitud y la servidumbre; la prohibición de la desaparición forzada y la tortura; ni las garantías judiciales indispensables para la protección de tales derechos.

\section{Derechos humanos y derecho penitenciario}

A partir de la reforma constitucional de junio de 2011, según se consigna en el artículo 18 de la CPEUM, el sistema penitenciario en México se organizará considerando como una exigencia fundamental el respeto de los derechos humanos; es decir, el funcionamiento integral de un establecimiento que forme parte de tal sistema, independientemente que sea administrado 
por autoridades locales o federales, deberá ser informado por las condiciones prácticas derivadas de los derechos humanos (por ejemplo, el derecho a la vida, a la integridad física y psíquica, el derecho a la salud, el derecho a la reinserción social, etcétera, todos ellos de titularidad reconocida a los internos). Consideramos, con Catalina Pérez Correa, ${ }^{23}$ que esta tarea representa un reto mayúsculo dado el carácter y significado social de una prisión. En buena medida la inclusión explícita de los derechos humanos en la política penitenciaria mexicana generará importantes cambios, entre ellos tal vez el más apremiante será el dirigido a resolver la ambivalencia que actualmente priva con relación a la finalidad de la pena, e inmediatamente después, el de la justiciabilidad de los derechos humanos de las personas recluidas.

\section{Control de constitucionalidad de la suspensión de derechos humanos y sus garantías}

Una novedad adicional consignada en el artículo 29 de la CPEUM es la facultad atribuida a la Suprema Corte de Justicia de la Nación para revisar oficiosamente la constitucionalidad de los decretos expedidos por el Ejecutivo en materia de restricción y suspensión en el ejercicio de derecho y garantías jurídicas a ellos asociados. Textualmente, el mencionado artículo establece: “(...) Los decretos expedidos por el Ejecutivo durante la restricción o suspensión, serán revisados de oficio e inmediatamente por la Suprema Corte de Justicia de la Nación, la que deberá pronunciarse con la mayor prontitud sobre su constitucionalidad y validez".

${ }^{23}$ La mencionada autora señala: "El problema de los derechos de las personas en reclusión (...), es uno de observancia y exigibilidad de esos derechos. Las cárceles son lugares ocultos, alejados de la sociedad, que, además, encierran a quienes como sociedad consideramos reprobables y, frecuentemente, merecedores de repudio. Las normas legales sobre los derechos de los y las detenidas rara vez se cumplen dentro de los penales, lo cual revelo no sólo un grave desfase entre lo que el derecho dice y lo que se hace, sino también una incompatibilidad con los valores del Estado social que supuestamente rigen nuestra Constitución". Pérez Correa, Catalina, "De la Constitución a la prisión. Derechos fundamentales y sistema penitenciario", en Carbonell, M., y Salazar, P. (coords.), La reforma constitucional de derechos humanos: un nuevo paradigma, México, UNAM, Instituto de Investigaciones Jurídicas, 2011, p. 253. 


\section{Derecho al debido proceso, asilo y refugio en favor de extranjeros}

Una asignatura pendiente en materia de derechos humanos ha sido el reconocimiento del derecho al debido proceso en favor de extranjeros cuando se pretende su expulsión del territorio mexicano. El Decreto incluye una enmienda al tristemente célebre artículo 33 constitucional por virtud de la cual todo acto de expulsión de extranjeros deberá fundamentarse legalmente, agotando una audiencia en la que el interesado pueda expresar lo que a su derecho convenga.

Artículo 33. Son personas extranjeras las que no posean las calidades determinadas en el artículo 30 constitucional y gozarán de los derechos humanos y garantías que reconoce esta Constitución. El Ejecutivo de la Unión, previa audiencia, podrá expulsar del territorio nacional a personas extranjeras con fundamento en la ley, la cual regulará el procedimiento administrativo, así como el lugar y tiempo que dure la detención.

Cabe señalar que en el mismo Decreto se establece la obligación a cargo del Congreso de la Unión de legislar en este sentido en un plazo máximo de un año contado partir del inicio de la vigencia del mismo.

Por otro lado, el artículo 11 de la CPEUM fue modificado para reconocer explícitamente el derecho de toda persona a solicitar asilo, recogiendo de esta manera un ítem fundamental del derecho internacional que protege a aquellos individuos que son sujetos de una persecución por parte de las autoridades del Estado del cual son originarios. ${ }^{24}$ Asimismo, el carácter de refugiado se encuentra protegido, a partir de la reforma, mediante el reconocimiento de derechos humanos específicos, lo cual es consignado en el mismo artículo 11 de la CPEUM que estamos analizando. De esta manera se manifiesta un claro alineamiento de la experiencia jurídica mexicana con un contenido fundamental del derecho internacional humanitario. Como se

24 En el propio artículo 11 de la CPEUM, cuya reforma estamos comentando, se establece que la operatividad del derecho de asilo será regulado por una ley específica. Con toda seguridad tal normativa habrá de referirse a las diversas facetas, o si se prefiere, manifestaciones reconocidas del derecho de asilo, tanto a nivel doctrinal como práctico, a saber: el derecho a ser admitido en el territorio de un Estado diverso al de origen; el derecho a permanecer en dicho territorio; el derecho a no ser expulsado; el derecho a no ser extraditado al país de origen donde se lleva a cabo la persecución, entre otros. Cfr., Ramírez, H., y Pallares, P., Derechos humanos, México, Oxford University Press, pp. 257-259. 
sabe, el corpus jurídico del derecho internacional humanitario está compuesto, fundamentalmente, por los cuatro Convenios de Ginebra de 1949 y dos protocolos adicionales. ${ }^{25}$ Sus disposiciones se orientan a aliviar la suerte que corren los heridos y enfermos de las fuerzas armadas en campaña; a vigilar la suerte que corren los heridos, enfermos y náufragos de las fuerzas armadas del mar; el trato correspondiente a los prisioneros de guerra; a la protección debida a las personas civiles en tiempo de guerra. ${ }^{26}$

\section{Efectos jurídicos de las recomendaciones emitidas por la Comisión Nacional de los Derechos Humanos y otros organismos afines en los estados de la República}

En materia de protección de los derechos humanos, los organismos tanto federal como estatales que tienen tal vocación, cuentan con un medio no vinculatorio conocido como recomendaciones; mucho se ha criticado tal carácter no vinculatorio, y ante ello, el Decreto incluye una enmienda al artículo 102 que establece la obligación a cargo de las autoridades o servidores públicos cuyos actos sean objeto de una recomendación, para fundar, motivar y hacer pública la no aceptación e incumplimiento de la recomendación en cuestión. Se añade a lo anterior la facultad de diversos órganos legislativos para solicitar la comparecencia de los titulares de lo órganos públicos frente a los que se emite la recomendación. ${ }^{27}$

25 Lo integran también el Protocolo facultativo de la Convención sobre los Derechos del Niño relativo a la participación de niños en los conflictos armados, el Tratado de Ottawa sobre las Minas Antipersonal, la Convención sobre Armas Químicas, la Convención sobre Ciertas Armas Convencionales y sus cinco Protocolos, la Convención sobre Armas Bacteriológicas y la Convención de La Haya para la protección de los bienes culturales en caso de conflicto armado y dos Protocolos adicionales para esta Convención.

${ }^{26}$ Moreno, Carmen, "La importancia de los convenios de Ginebra en la evolución del derecho internacional público", en Fraidenraij, S. y Méndez, R., Elementos de derecho internacional humanitario, México, UNAM, Instituto de Investigaciones Jurídicas, 2001, p. 24.

27 Artículo 102. (...)

(...)

Los organismos a que se refiere el párrafo anterior, formularán recomendaciones públicas, no vinculatorias, denuncias y quejas ante las autoridades respectivas. Todo servidor público está obligado a responder las recomendaciones que les presenten estos organismos. Cuando las recomendaciones emitidas no sean aceptadas o cumplidas por las autoridades o servidores públicos, éstos deberán fundar, motivar y hacer pública su negativa; además, la Cámara de Senadores o en sus recesos la Comisión Permanente, o 


\section{Nuevas facultades reconocidas en favor de la Comisión Nacional} de los Derechos Humanos

Acerca de esta cuestión, el Decreto incluye varias enmiendas al artículo 102, ampliando las facultades de la Comisión Nacional de los Derechos Humanos, la cual podrá investigar hechos que constituyan violaciones graves a los derechos humanos y, en su caso, realizar las denuncias y quejas ante las autoridades respectivas; así mismo, a partir de la reforma la Comisión Nacional de los Derechos Humanos será competente para conocer de violaciones a los derechos humanos en tratándose de asuntos de materia laboral, y podrá además controvertir tratados internacionales que vulneren derechos humanos a través del mecanismo conocido como acción de inconstitucionalidad y consagrado en el artículo 105, fracción II, inciso g de la CPEUM.

\section{La recepción del derecho internacional de los derechos humanos y la política exterior mexicana}

Finalmente, el Decreto de reforma eleva los estándares internacionales de esta materia a rango constitucional de manera explícita. El ya citado artículo 10. establece que para el caso de los derechos humanos tanto la CPEUM como los tratados internacionales de los que México sea parte, son las fuentes primarias. Como se ha dicho, en materia de derecho internacional de derechos humanos encontramos distinto tipo de resoluciones. Algunas del hard law como sentencias contra México por la Corte Interamericana de Derechos Humanos (CrIADH), otras del soft law, como recomendaciones de interpretación sobre el alcance de los derechos de la niñez. Entonces, y considerando el contenido de la reforma: ¿todo el derecho internacional de derechos humanos tiene la misma validez jurídica en México? ¿Todas las recomendaciones y resoluciones de organismos internacionales vinculan a México para interpretar su derecho interno de la misma manera? Pensamos que no. El grado de vinculación de las resoluciones de organismos internacionales varía en función de la naturaleza

las legislaturas de las entidades federativas, según corresponda, podrán llamar, a solicitud de estos organismos, a las autoridades o servidores públicos responsables para que comparezcan ante dichos órganos legislativos, a efecto de que expliquen el motivo de su negativa. 
jurídica de dichas resoluciones. Esquemáticamente puede explicarse de la siguiente manera: ${ }^{28}$

a) Siempre será vinculatorio el cumplimiento de sus obligaciones convencionales en materia internacional.

b) Siempre deberá aplicar las normas del ius cogens reconocidas en el derecho internacional de los derechos humanos.

c) Son vinculatorias las sentencias de procesos jurisdiccionales en las que el Estado haya sido condenado.

d) Si el Estado no hace suya y aplica una recomendación hecha directamente a él, deberá, por el principio de buena fe del derecho internacional y sus obligaciones constitucionales, fundamentar que su solución alternativa ofrecida protege más y mejor los derechos humanos.

e) Para las normas del soft law, el Estado tiene el deber de tomarlas como parámetro o criterio interpretativo; de tal manera que tendría que justificar el uso de un parámetro distinto o una mejor interpretación.

En todo caso, el modo en que esto se aplicará todavía está a debate y se irá precisando. Por lo pronto, la Suprema Corte de Justicia de la Nación (SCJN) ha estudiado los aspectos vinculatorios de la sentencia de la CrIADH Radilla Pacheco vs. México ${ }^{29}$ aplicables al Poder Judicial: para el caso de las medidas de reparación, se presentó en el Pleno del tribunal supremo una propuesta de criterios que pueden servir para dilucidar la solución para este tema en cuanto al valor jurídico y alcance de dichas sentencias internacionales. Sobre esa base, extendemos nuestro análisis al resto del derecho internacional de los derechos humanos. En estos casos, cuando México sea parte del proceso jurisdiccional internacional, sí hay obligación de cumplir con la sentencia y sus estándares (sentencias, opiniones consultivas, medidas provisionales). Para el resto de jurisprudencia de la CrIADH, y en consecuencia, el resto de resoluciones internacionales no jurisdiccionales, el derecho internacional de los derechos humanos es

28 Cfr. Ramírez, Hugo y Pallares, Pedro, op. cit., p. 379.

29 Corte Interamericana de Derechos Humanos, Caso Radilla Pacheco vs. México. Excepciones Preliminares, Fondo, Reparaciones y Costas, sentencia del 23 de noviembre de 2009, serie C, núm. 209. 
altamente significativo tanto como criterio interpretativo relevante de los derechos humanos, como en cuanto parámetro para cumplir con las obligaciones derivadas de los tratados. ${ }^{30}$

Finalmente, es necesario hacer mención que la reforma constitucional en comento ha incluido al conjunto de actos que configuran la política exterior mexicana. En efecto, uno de los principios normativos que deberá observar el Poder Ejecutivo en esta materia será la promoción y respeto de los derechos humanos. ${ }^{31}$ Con esto, como hemos dicho previamente, México supera cierta posición nacionalista y defensiva que valoraba de manera tal vez excesiva el significado práctico del concepto soberanía, para asumir con mayor claridad una postura colaborativa e internacionalista en materia de derechos humanos. ${ }^{32}$

\section{LA REFORMA CONSTITUCIONAL EN MATERIA DE DERECHOS HUMANOS Y LA PRAXIS DE LA DIGNIDAD}

Después de hacer una breve referencia a los principales instrumentos legislativos que figuran como los antecedentes más relevantes de la reforma en materia de derechos humanos, así como a sus novedades más destacadas, ahora corresponde abordar lo relativo a la dignidad humana, ya que es un tema de estudio y análisis obligado siempre que se habla, con seriedad, de los derechos humanos ${ }^{33} \mathrm{y}$, además, porque fue uno de los puntos menos

30 Versión estenográfica de la Sesión Pública Ordinaria del Pleno de la SCJN, del 31 de agosto de 2010, intervención del ministro José Ramón Cossío.

31 Cfr. artículo 89, fracción X.

32 El recuento histórico de este itinerario se desarrolla con gran detalle en: Saltalamacchia, N., y Covarrubias, A., "La dimensión internacional de la reforma de derechos humanos: antecedentes históricos", op. cit., passim.

33 No nos es ajeno que un sector importante de la doctrina jurídica sostiene precisamente lo contrario. El punto de partida que comparte la mayoría de tales autores se vincula a las dificultades en reconocer objetividad a ideas como dignidad humana, o valores como la justicia: en ambos casos se estaría frente a conceptos vacíos que carecen de datos empíricos que posibiliten un conocimiento certero acerca de lo que son, y su relación con los derechos humanos. En este sentido, Norbert Hoerster señala: "lo especial del concepto de la dignidad humana (...) consiste justamente en que no se trata, en modo alguno, de un concepto descriptivo. La consecuencia de esto es que las controversias de aplicación son necesariamente controversias de valoración ética y, en tanto tales, por razones de principio, son, en último término, inaccesibles a una decisión científico-racional. Norbert Hoerster, En defensa del positivismo jurídico, Barcelona, Gedisa, 2000, p. 99. 
atendidos por el constituyente en la discusión, análisis y aprobación del texto constitucional.

Basta ingresar la palabra "dignidad" en un buscador de Internet para tener una infinidad de portales y documentos que abordan el tema. También es fácil encontrar esa palabra en los libros de ética más encumbrados, o en las Constituciones o instrumentos internacionales avocados a los derechos humanos más refinados. Sin embargo, las finalidades y contenidos con que se le utiliza varían mucho unas de otras ya que normalmente se le utiliza como una figura decorativa para embellecer determinados discursos políticos, sociales, académicos o religiosos.

Por el tema que ahora nos ocupa solamente haremos referencia a uno de los usos o sentidos en los que tiene cabida la dignidad. Es el caso de la dignidad en sentido ontológico, y a partir de él, desprenderemos sus significados prácticos. ${ }^{34}$

\section{Dignidad humana en sentido ontológico}

La dignidad humana, en un sentido ontológico, se refiere a la importancia y excelencia del ser del individuo humano, que lo diferencia y lo pone en un nivel de superioridad respecto de otros seres, haciendo irrelevante la concurrencia de otras condiciones o circunstancias que los puedan asemejar o aproximar. Este sentido tiene implicaciones prácticas de vital importancia: la igualdad esencial de todos los seres humanos, así como constituir el fundamento de los derechos humanos. De estas implicaciones nos ocuparemos más adelante.

La dignidad ontológica radica en que el acto de ser, del que deriva la condición misma del ente, no sólo es la actualidad fuera de la cual nada existe, sino también es el fundamento de todo valor porque fuera del ser el mismo valor es nada, no hay valor sin ser. Dicho con otros términos: el ser es el acto constitutivo más radical, aquello por lo que las cosas y las personas son, es el acto más primigenio y más íntimo del ente, que desde

34 Véase Ballester, Manuel, "El ser personal como telos en el fundamento de la acción humana", Actas de las Jornadas de la Sociedad Internacional Tomás de Aquino, Barcelona, Balmes, Barcelona, 1993, vol. I, p. 193. 
dentro le confiere toda su plenitud; ${ }^{35}$ así, la perfección de la persona deriva de la peculiar alcurnia del ser que la constituye. ${ }^{36}$

Cada persona es un fin en sí mismo y su dignidad es completamente independiente de toda "función", ya que se fundamenta en el carácter personal del hombre. La auténtica independencia de la persona estriba en que a ningún hombre le corresponde juzgar si otro hombre posee o no los rasgos fundamentales de la personalidad. No es lícito añadir cualquier criterio adicional. ${ }^{37}$ En efecto, la persona no es algo cualitativamente descriptible, sino que es "alguien", cuya naturaleza es esencialmente una naturaleza racional. Por ello, no existe ningún motivo para no considerar como personas y tratarlos como tales a aquellos que poseen la misma naturaleza, aunque todavía no la hayan desarrollado, o bien se haya hecho de una manera defectuosa. Los que no poseen o no pueden desarrollar la capacidad de razonar — como, por ejemplo, algunas personas enfermas-, o los que aún no han desarrollado esa capacidad no son, de ninguna manera, seres de otro tipo; a partir de esta premisa cabe estar atentos al hecho de que los débiles, los improductivos, los discapacitados, los niños, los enfermos, los no nacidos podrían irse excluyendo progresivamente de la definición de persona, lo que podría fácilmente justificarse por razones de Estado y, en última instancia, de conveniencia; pero la dignidad, a diferencia del valor cuantitativo, no es conmensurable. En todo caso, estos seres humanos están necesitados de nuestra ayuda, y nuestra propia dignidad como personas no se hará más clara por otra cosa que por la ayuda que prestemos, aunque no haya en ellos nada que despierte nuestra simpatía. ${ }^{38}$

En definitiva, ser persona no es una determinación cualitativa, sino que persona es aquél que posee dichas cualidades. Es esencial para la naturaleza humana el ser poseída por una persona, es decir, por un "alguien". La personalidad no es de ninguna manera un estado de cosas cualitativo, descriptible por medio de determinados predicados, sino que

35 Ibidem, pp. 134-142.

${ }^{36}$ Cfr. Melendo, Tomás, Dignidad humana y bioética, Navarra, EUNSA, 1999, pp. 99 y ss.

37 Spaemann, Robert, Lo natural y lo racional, Madrid, Rialp, 1989, pp. 49 y 50.

38 Spaemann, Robert, “Son todos los hombres personas?”, Cuadernos de Bioética, España, vol. VIII, núm. 31-3ª julio-septiembre de 1997, pp. 1027-1033. 
determinados estados de cosas descriptibles cualitativamente constituyen para nosotros signos por los que las personas se dan a conocer. ${ }^{39}$

\section{Praxis de la dignidad humana}

La dignidad humana no se limita a ser la nomenclatura que adorna un conjunto de reglas para el trato entre individuos; muy por el contrario, se trata de una realidad de carácter ontológico, de la cual deriva el sentido práctico más auténtico y objetivo con el que podemos contar. ${ }^{40}$ Como afirma Gregorio Péces-Barba, no sin razón la dignidad humana fundamenta la ética pública y se constituye, además, como un prius de los valores políticos y jurídicos, y de los principios y derechos que derivan de esos valores tales como: la libertad, la igualdad, la solidaridad y la seguridad que sólo alcanzan su plenitud cuando su contenido moral se positiviza en normas jurídicas de máximo nivel. ${ }^{41}$

Puede decirse que la ultimidad fundamentadora de la dignidad no la tiene ningún otro valor, por ello no se le debe situar en el mismo nivel que la libertad, la igualdad o el pluralismo político $;{ }^{42}$ de acuerdo con ello destacan, como manifestaciones de la función práctica de la dignidad humana la fundamentación del orden jurídico, orientando su interpretación e integración, y la validación sustantiva de los derechos humanos, incluyendo los deberes a ellos correlativos, aflorando así su significado práctico de un supra-valor o meta-norma sobre la que se desarrollan tales derechos, ya como naturales, ya como positivos. ${ }^{43}$

39 Spaemann, Robert, Ética: cuestiones fundamentales, 5a. ed., España, EUNSA, 1998, p. 86.

40 Cfr. Spaemann, Robert, Lo natural y lo racional, op. cit., p. 19.

41 Peces-Barba Martínez, Gregorio, La dignidad de la persona desde la filosofía del derecho, Madrid, Dykinson, 2003, pp. 12 y 67, y Peces-Barba Martínez, Gregorio, Ética, poder y derecho, México, Fontamara, 2004, p. 62. También véase Fernández García, Eusebio, Teoría de la justicia y derechos humanos, Madrid, Debate, 1987, p. 120, y Fernández García, Eusebio, Dignidad humana y ciudadanía cosmopolita, Madrid, Dykinson, 2001, p. 25.

${ }^{42} C f r$. W. Maihofer, "Die Würde des Menscgen als Zweck des Staates", $A C F S, 12-2$, 1972, pp. 56-58. Citado por Serna, Pedro, "La dignidad de la persona como principio de derecho público", XXV Jornadas Chilenas de Derecho Público, Valparaíso, Edeval, 1995, t. I, p. 366.

${ }^{43}$ Cfr. González Pérez, Jesús, La dignidad de la persona, Madrid, Civitas, 1986, pp. 87 y 94 
Los estudiosos de la materia sostienen que los derechos humanos fueron concebidos después de un largo camino por encontrar el medio para plasmar en el derecho la dignidad de la persona y protegerla. ${ }^{44}$ A partir de entonces son la expresión jurídica de la dignidad humana y se constituyen como el paradigma ético para el ejercicio del poder político, en un principio de legitimación. ${ }^{45}$

La conciencia universal acerca de la dignidad de la persona se ha proyectado en diversos planos. En el ámbito internacional, como explica Antônio Cançado Trindade, puede afirmarse la presencia de una era de los derechos humanos, consolidada a lo largo de las últimas cinco décadas, a partir del convencimiento jurídico global sobre el reconocimiento de que el respeto de los derechos humanos es la mejor medida del grado de civilización. ${ }^{46}$ Entre otros factores que evidencian la realidad de esta afirmación puede destacarse: a) el esfuerzo permanente por conocer el grado de respeto de los derechos, el cual ha dado como resultado que la movilización de la opinión pública internacional frente a casos graves de violación de derechos sea expedita; b) la auténtica configuración de un ius gentium, evidenciada en la tendencia a la criminalización de las violaciones graves de los derechos humanos, a través del funcionamiento de la jurisdicción universal; c) la consolidación de un orden público internacional que gira en torno a la protección y respeto de los derechos humanos, mediante el cual se postula el reconocimiento de los tratados de derechos humanos como una fuente peculiar de obligaciones para los Estados, sobre todo por su carácter objetivo, es decir, al margen de la bilateralidad típica derecho-deber, y superando la objeción a su cumplimiento fundamentada en la soberanía.

Por otro lado, en el plano del derecho interno es notoria la disposición de infinidad de países que, a la hora de dictar nuevas constituciones o enmendar las ya vigentes, reconocen a la persona no sólo como mero participante de la vida política del Estado, sino también como un ser de especial consideración que necesita de la protección y tutela estatal que le garantice los mínimos éticos que le permitan desarrollar sus potencialidades intelectuales y satisfacer sus necesidades sociales, espirituales, económicas, etcétera.

44 Cfr. Talavera, Pedro, "Historia de su nacimiento", Megías, J., Manual de derechos humanos, Thomson-Aranzadi-Cizur Menor, 2006, p. 58.

45 Cfr. Martínez Bullé-Goyri, Víctor M., (Coord.), Diagnóstico genético y derechos humanos, UNAM, México, 1998, pp.166-167.

${ }^{46}$ Cfr. Cançado, Antônio, El derecho internacional de los derechos humanos en el siglo XXI, México, Jurídica de las Américas, 2009, p. 417. 
Como ejemplos de lo anterior pueden citarse la Ley Fundamental de la República Federal de Alemania de 1949, la Constitución Española de 1978, y más reciente la Constitución del Perú de 1993. Esas leyes fundamentales ponen la idea de dignidad humana en la cúspide jurídica y política del Estado, es decir, han positivisado el principio ético rector de los derechos humanos, y no lo han hecho a modo sólo de prohibición, facultad u obligación, sino como noción basamental, motivo por el cual su contenido no está dado por la fuente jurídica, que es mero garante, sino que su contenido deriva de una reflexión filosófica de más alto nivel. Como explica Hans Michael Baumgartner:

La así expresada garantía constitucional de la dignidad humana (...) define básicamente tanto la relación de la persona con el Estado como la relación recíproca de las personas. Es el fundamento de una comunidad libre, y al mismo tiempo, solidaria. Vincula el poder estatal a la autocomprensión de la persona, que va más allá de la conexión medio-fin. ${ }^{47}$

De esta forma, hoy tenemos mayor conciencia acerca del significado práctico de la dignidad humana: como la expresión más acabada de la necesidad universal de establecer el respeto de la persona, y como premisa antropológica del Estado constitucional del derecho. Todo esto se concreta en diversas funciones de las cuales, con César Landa, podemos destacar: a) la función ordenadora: aquí, alrededor de la dignidad humana, se configura un orden fundamental, es decir, una serie de razones y justificaciones básicas para la acción, que dan sentido al dinamismo propio de entidades públicas y privadas; b) la función integradora: que supone reconocer que la dignidad humana genera unidad de propósito al interior de una comunidad concreta; adicionalmente, a partir de la función integradora de la dignidad se revela su fuerza de duración, misma que otorga estabilidad a las instituciones, en primer lugar, a la Constitución; c) la función limitadora: que da cuenta del significado práctico de la dignidad, como antídoto frente al autoritarismo de cualquier clase. ${ }^{48}$

47 Baumgartner, Hans, "Libertad y dignidad humana como fines del Estado", en Höffe, O., y Isensee, J. (coords.), Panorama de filosofia politica. Contribuciones alemanas, Konrad Adenauer Stiftung, 2002, p. 24.

48 Cfr., Landa, César, "Dignidad de la persona humana", Cuestiones Contitucionales. Revista Mexicana de Derecho constitucional, núm. 7, 2002, pp. 124-128. 


\section{La dignidad humana en la reforma constitucional en materia de derechos humanos}

La reforma en materia de derechos humanos a la que nos hemos referido en todo este trabajo supuso una magnífica oportunidad para que el constituyente permanente reconociera a la dignidad humana como supravalor o metanorma del sistema jurídico. Desde nuestro punto de vista quedó corto en este propósito ya que si bien se han incluido principios interpretativos como el denominado pro personae, que sin duda contribuye a la hermenéutica del texto constitucional en pos del respeto, protección y promoción de la persona en virtud de su dignidad, la reforma no se refiere expresamente a la dignidad humana como principio o valor del orden jurídico-político como en los tres ordenamientos antes citados. Su mención en el artículo 1o. es meramente retórica y fortuita sin que se pueda apreciar su alcance y estimación reales en el sistema jurídico. Esta omisión, por tanto, la consideramos una sombra de la aludida reforma, pues en ninguna de las etapas del proceso de enmienda constitucional fue siquiera planteado el tema por los órganos implicados.

\section{CONCLUSIONES}

Primera. La reforma constitucional en materia de derechos humanos que se materializó con la publicación en el Diario Oficial de la Federación el 10 de junio de 2011 se inscribe en un proceso de renovación de la Carta Magna ante los nuevos escenarios políticos y sociales, esto es lo que se ha llamado "reforma del Estado". No obstante, dicho proceso ha sido pausado y fraccionado porque en varias ocasiones fracasó el intento de promulgar una nueva constitución. De este modo, la reforma en comento tiene la misma intención que otras que la antecedieron, tal es el caso, por ejemplo, de las reformas concernientes a la Suprema Corte de Justicia y al Consejo de la Judicatura Federal, publicadas en el Diario Oficial de la Federación el 31 de diciembre de 1994 y el 22 de agosto de 1996; la reforma en materia municipal, publicada el 23 de diciembre de 1999; la relativa a la responsabilidad patrimonial del Estado, publicada el 14 de junio de 2002; la electoral, publicada el 13 de noviembre de 2007; la de justicia penal, publicada el 18 de junio de 2008 y; finalmente, la de amparo, publicada el 6 de junio de 2011. 
Segunda. La reforma constitucional en materia de derechos humanos tuvo varios antecedentes legislativos que enriquecieron la discusión y, en consecuencia, su alcance y contenido. Los más relevantes son: $i$ ) la Comisión de Estudios para la Reforma del Estado conformada el 14 de junio de 2000 que proponía, principalmente, el reconocimiento del carácter universal de los derechos humanos; ii) la iniciativa presentada a la Cámara de Senadores el 22 de marzo de 2004, que planteaba fortalecer el sistema constitucional de los derechos humanos y replantear la jerarquía de los tratados internacionales en esa materia; iii) la iniciativa presentada por el Ejecutivo a la Cámara de Senadores el 27 de abril de 2004, que advierte un rezago en la CPEUM al no reconocer expresa y categóricamente los derechos humanos; iv) el dictamen de la Cámara de Diputados del 23 de abril de 2009 que, en términos generales: a) señala la necesidad de incorporar un régimen de protección más amplio acorde a las obligaciones internacionales suscritas, $b$ ) sustituye el término "individuo" por el de "persona", c) establece diversas obligaciones del Estado en esa materia $\mathrm{y}, d$ ) incorpora el principio pro personae o pro hominae; $v$ ) la iniciativa presentada a la Cámara de Senadores el 23 de febrero de 2010, que propone modificaciones al proceso de suspensión de garantías; vi) el dictamen de la Cámara de Senadores del 7 de abril de 2010 que, fundamentalmente, plantea: a) incluir en el texto constitucional un elenco de derechos que no podrán restringirse ni suspenderse, $b$ ) adoptar el principio de "interpretación conforme", y c) considerar algunas obligaciones del Estado, particularmente lo relativo a reparar las violaciones a los derechos humanos y; vii) el dictamen de la Cámara de Diputados del 13 de diciembre de 2010, que apela por contemplar todos los tratados internacionales debidamente ratificados y las preferencias sexuales como posibles formas de discriminación y, además, incluye el derecho a la vida dentro de la lista de derechos insuspendibles.

Tercera. El concepto "derechos humanos" ofrece ventajas que más allá de ser semánticas son eminentemente prácticas, pues posibilita una relación entre personas no condicionada por los ordenamientos legales. Es decir, todo lo relacionado a la protección, defensa y promoción de los derechos humanos no está limitado por texto jurídico alguno; por tanto, no son tareas que sólo competan a las diversas autoridades estatales, sino también, y de modo muy especial, a la sociedad en su conjunto. La praxis de la dignidad de todo ser humano, y en ésta medida el respeto y promoción de los derechos que en ella se fundamentan, a partir de la reforma constitucional ya 
no sólo es vertical o de subordinación (gobernante-gobernados), sino de horizontal o de corresponsabilidad (entre todo individuo).

Cuarta. Una de las novedades que comporta una ardua labor para el futuro es la que tiene que ver con las obligaciones, explícitamente reconocidas, de promoción, respeto, protección, garantía, prevención, investigación, sanción y reparación en lo relativo a los derechos humanos. Esto con un carácter exponencial ya que, por un lado, aluden a "todas las autoridades" y con ello deben entenderse comprendidos los tres órdenes de gobierno, sin limitación alguna, y por otro lado, cada una de esas acciones conlleva otras tantas en las que el compromiso de la autoridad y de la sociedad no puede ser menor a la intención del constituyente. En consecuencia, consideramos que esta es una de las partes medulares y fundamentales de la reforma constitucional, en la que lejos de haber concluido con el reconocimiento de los derechos humanos por la CPEUM apenas ha marcado el inicio de un largo y sin dudas, complejo camino que hay que recorrer.

Quinta. La praxis de los derechos humanos que, como se ha dicho, impele tanto a la relación gobernante-gobernados como a la que tienen éstos en cumplimiento de las obligaciones constitucionales ya citadas, tiene su soporte en los principios de universalidad, interdependencia, indivisibilidad, progresividad y pro personae reconocidos y fundamentados por el derecho internacional y la doctrina jurídica.

Sexta. Un elenco de derechos que no podrán restringirse ni suspenderse, modificaciones al proceso de suspensión de garantías, el derecho al debido proceso en favor de los extranjeros cuando se pretenda su expulsión del territorio nacional, lo referente a las recomendaciones de las comisiones de derechos humanos, la facultad de investigación que se atribuye a la Comisión Nacional de los Derechos Humanos en esa materia y la incorporación a rango constitucional de las normas internacionales de derechos humanos también constituyen novedades dignas de elogio, pues con estos rubros en particular la reforma constitucional de mérito ha modificado la forma de concebir a los derechos humanos y, quizá con mayor relevancia, en los mismos términos ya expuestos, su praxis dentro de los sistemas político y jurídico.

Séptima. La incorporación a rango constitucional de las normas internacionales de derechos humanos subsana, de algún modo, la omisión del constituyente ya que prácticamente todos esas normas -seguidas de diversas constituciones o leyes fundamentales- promulgadas después de los trágicos sucesos de la Segunda Guerra Mundial, consideran a la dignidad 
humana como la piedra angular de los derechos humanos. Esto demuestra la preeminencia que tiene no sólo para la fundamentación iusfilosófica de estos, sino también para su praxis misma.

Octava. Los derechos humanos son el producto del esfuerzo de la sociedad moderna por plasmar en el derecho la dignidad de la persona y protegerla. Éstos son, en definitiva, la expresión jurídica de la dignidad humana al constituirse en el paradigma ético tanto del ejercicio del poder político del gobernante, como de la libertad individual de los ciudadanos. Pese a las bondades que ha traído la reforma constitucional para la protección, defensa y promoción de los derechos humanos en nuestro país, existen algunos temas que no fueron suficientemente atendidos por el constituyente, no obstante que era el momento y ocasión propicios para ello. Tal es el caso de la dignidad humana entendida como principio práctico fundamental.

Fecha de recepción: 11 de enero de 2011.

Fecha de dictamen: 7 de mayo de 2012. 